\title{
JRC2017-2248
}

\section{RESULTS OF A DIESEL MULTIPLE UNIT FUEL TANK BLUNT IMPACT TEST}

\author{
Karina Jacobsen \\ Michael Carolan \\ Volpe National Transportation Systems Center \\ United States Department of Transportation \\ Cambridge, Massachusetts, USA
}

\begin{abstract}
The Federal Railroad Administration's Office of Research and Development is conducting research into passenger locomotive fuel tank crashworthiness. A series of impact tests is being conducted to measure fuel tank deformation under two types of dynamic loading conditions - blunt and raking impacts. The results of this research program assist in development of appropriate standards for puncture resistance requirements to be applied to alternatively-designed fuel tanks, such as on diesel multiple unit (DMU) passenger rail equipment. This paper describes the results of the first blunt impact test performed on a DMU fuel tank.
\end{abstract}

On June 28, 2016, FRA performed a dynamic impact test of a fuel tank from a DMU rail vehicle. The test was performed at the Transportation Technology Center (TTC) in Pueblo, Colorado. An impact vehicle weighing approximately 14,000 pounds and equipped with a 12-inch by 12-inch impactor head struck the bottom surface of a DMU fuel tank mounted vertically on an impact wall. The impact occurred on the bottom of the fuel tank at a location centered on two baffles within the fuel tank. The target impact speed was $11.5 \mathrm{mph}$, and the measured impact speed $11.1 \mathrm{mph}$. The test resulted in a maximum indentation of approximately 8 inches, the bottom of the tank bending away from the wall, and buckling of several internal baffles. Following the test, the tank was cut open to inspect the damage to the internal structure. This revealed that the buckling behavior of the baffles was isolated to the baffles immediately adjacent the impact location, each one buckling as the tank deformed inward.

Prior to the test, finite element analysis (FEA) was used to predict the behavior of the tank during the test. The FE model of the tank required material properties to be defined in order to capture plastic deformation. The combination of metal plasticity, ductile failure, and element removal would permit the model to simulate puncture for this tank at sufficiently-high impact speeds. The pre-test FE model results compared very favorably with the test measurements, and both the pre-test model and the test resulted in similar modes of deformation to the DMU fuel tank. Following the test, material coupons were cut from undamaged areas of the fuel tank and subjected to tensile testing. The post-test FE model was updated with the material behaviors from the post-test material testing.

This test is part of a research program investigating puncture resistance of passenger locomotive fuel tanks. The objective of this research program is to establish the baseline puncture resistance of current locomotive fuel tanks under dynamic impact conditions and to develop performance requirements for an appropriate level of puncture resistance in alternative fuel tank designs, such as DMU fuel tanks.

Future tests are planned within this research program. The lessons learned during the series of tests support finite element (FE) modeling of impact conditions beyond what was tested. Additional tests investigating the puncture resistance of fuel tanks during sideswipe or raking collisions are also planned.

\section{INTRODUCTION}

Passenger fuel tank crashworthiness research is being conducted as part of the Federal Railroad Administration's (FRA's) Equipment Safety Research program. Current research is particularly focused on assessing fuel tank crashworthiness during dynamic impacts in order to assess the applicability of current fuel tank standards on the growing number of alternative passenger equipment fuel tank designs, like those on DMUs.

This material is declared a work of the U.S. Government and is not subject to copyright protection in the United States. Approved for public release; distribution is unlimited. 
DMU fuel tanks are smaller than conventional passenger locomotive fuel tanks, but are currently required to meet the same standards and regulations. A research program has been set up to first assess conventional passenger locomotive fuel tanks and then assess alternatively-designed passenger equipment fuel tanks.

The research program follows the methodology illustrated in Figure 1, which begins with developing a baseline measure of existing design performance for a given scenario and extends to developing improvements for enhancing safety performance for that scenario.

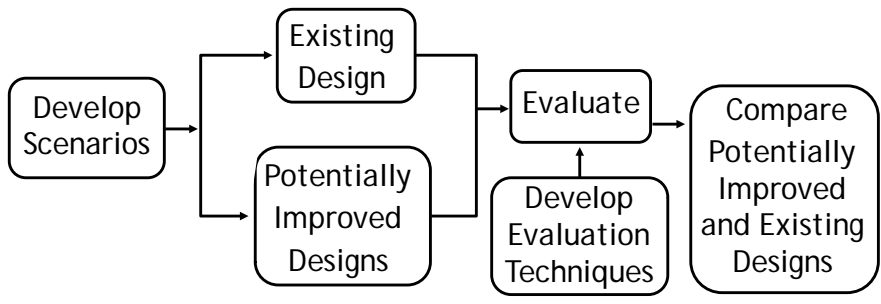

Figure 1. Flow Diagram of Crashworthiness Research Methodology

To develop scenarios for the fuel tank research, FRA conducted a survey of accidents and derailments in the U.S. over the last two decades [1]. The survey was conducted using the FRA accident database and includes freight and passenger train fuel tanks that reported a fuel tank rupture during a collision or derailment. Two key findings should be noted from the results of this survey. First, a fuel tank rupture during a train collision or derailment may result in a fire, which presents additional threats to the survivability of passengers and crew as they egress from the collision wreckage. With passenger operations, the risk profile is higher with the presence of more people onboard the consist and their proximity to the ejected fuel. The second key finding is that each fuel tank impact scenario can be categorized by its resultant loading type, of which there are two general loading conditions leading to punctures: blunt impacts and raking impacts.

A series of full-scale tests is underway to test fuel tanks under the identified impact types. A test setup for a blunt impact was designed and has been tested on three retired passenger locomotive fuel tanks. The fuel tank specimens were removed from the FRA's F40 locomotives at TTC and used for testing to develop the details of a repeatable blunt impact test. A second outcome of these first blunt impact tests was to gather initial information on the performance of conventional fuel tanks under a dynamic impact.

This paper discusses the test of a blunt impact load applied to an alternative locomotive fuel tank. For this research, new fuel tanks were purchased from a manufacturer of Diesel Multiple Unit (DMU) equipment operated in the U.S.

\section{TEST SCENARIO - BLUNT IMPACT}

The first round of preliminary testing of conventional fuel tanks was conducted in October 2013 and August 2014 at TTC in Pueblo, Colorado. The first two tests were performed at low speeds, 4.5 and $6.2 \mathrm{mph}$, chosen to impart permanent deformation to the tank and measure the force-deflection characteristics [2, 3, 4]. These preliminary tests provided valuable initial information on the variance of tank performance based on design details. A third test was conducted on August 20, 2014 with an identical test setup, on a retired conventional fuel tank, at a speed of $11.2 \mathrm{mph}$ [5].

The second phase of testing in this program is focused on DMU fuel tanks. On June 28, 2016, a blunt impact was conducted on a DMU tank at $11.1 \mathrm{mph}$, with a similar setup as the three prior tests of conventional passenger locomotive fuel tanks. This paper describes and discusses the test setup, pre-test modeling, test and model results, and planned next steps for this DMU fuel tank. Discussion of the previous tests and analyses on conventional locomotive fuel tanks can be found in References [1] through [5].

\section{Objective}

The key objective of the impact testing of fuel tanks is to examine the gross response of the fuel tanks to a given impact type. The blunt impact test was designed to characterize each test specimen's deformation behavior when impacted on the bottom sheet. The overall approach to characterizing the deformation behavior includes:

1. Develop an analytical model of the fuel tank specimen based upon known design details.

o Use an analytical model to plan for test.

o Estimate possible fuel tank behavior under test impact conditions.

2. Apply a blunt, dynamic load to the bottom surface of a fuel tank specimen.

o Measure the force-deflection behavior of the tank with specified instrumentation.

o Record mode of deformation with high-speed and conventional video cameras.

3. Post-test examination to characterize structural deformation of tank exterior and interior.

4. Update model with actual test speed and tank properties.

The outcome of this process can be used to make a comparison between fuel tanks of different designs, with analysis techniques being used to provide additional information on the fuel tank behavior. Modeling can also be used to simulate additional impact conditions beyond what was tested, providing additional points of comparison between different designs. The results of the first two tests of passenger locomotive fuel tanks give preliminary insight into the deformation patterns of conventional fuel tanks and also helped to demonstrate the functionality of the dynamic blunt impact test setup at TTC. The third (conventional locomotive) and fourth (DMU) tests using the same impactor at around $11 \mathrm{mph}$ provide data that allows a comparison of the performance of a conventional passenger locomotive fuel tank

This material is declared a work of the U.S. Government and is not subject to copyright protection in the United States. Approved for public release; distribution is unlimited. 
with that of a DMU fuel tank under the same dynamic impact conditions to be made.

\section{Test Setup}

Figure 2 shows the test setup for the blunt impact test. The rail cart, equipped with a 12 -inch by 12 -inch indentor on the front end weighs approximately $14,000 \mathrm{lbs}$. Additional details of the test setup are described in a paper on tests for tanks 202 and 232 [2]. The test wall mounting setup allows for each test specimen to be mounted through its existing attachment points, as it would to a locomotive or DMU carbody, and positioned to impact the bottom surface of the tank with a rigid indenter at a predetermined location. A rail cart fitted with a rigid 12-inch by $12-$ inch impactor is released to roll along the tracks, impacting the bottom of the fuel tank of a specific location, near the desired impact speed. Transportation Technology Center Inc. (TTCI) can control the impact speed to within $+/-2 \mathrm{mph}$. Figure 2 shows a schematic illustration of the test setup with the impact cart, fuel tank, and reaction wall.

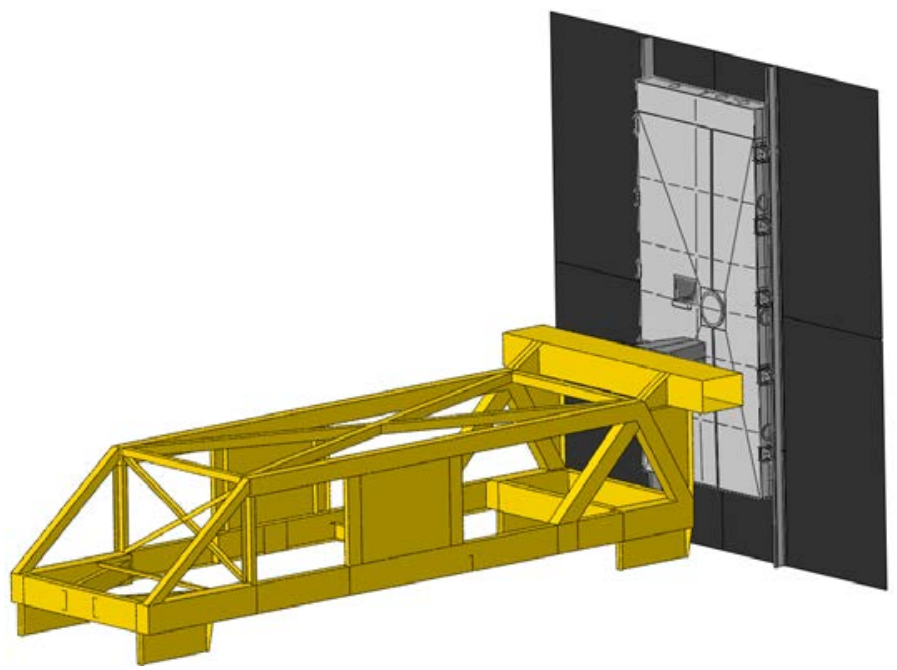

Figure 2. Schematic Showing Test Setup

For the test of the DMU fuel tank, the mounting scheme was chosen to attempt to replicate the mounting arrangement that would be found on an actual in-service DMU. Due to the position of the mounting brackets on the tank itself, two Cchannels were first attached to the rigid test wall to provide the necessary clearance between the tank and the wall. The tank was attached to the C-channels through mounting hardware that was provided by the DMU tank manufacturer and which featured a rubber bushing through which the attachment bolt passed. A typical mounting arrangement is shown in Figure 3.
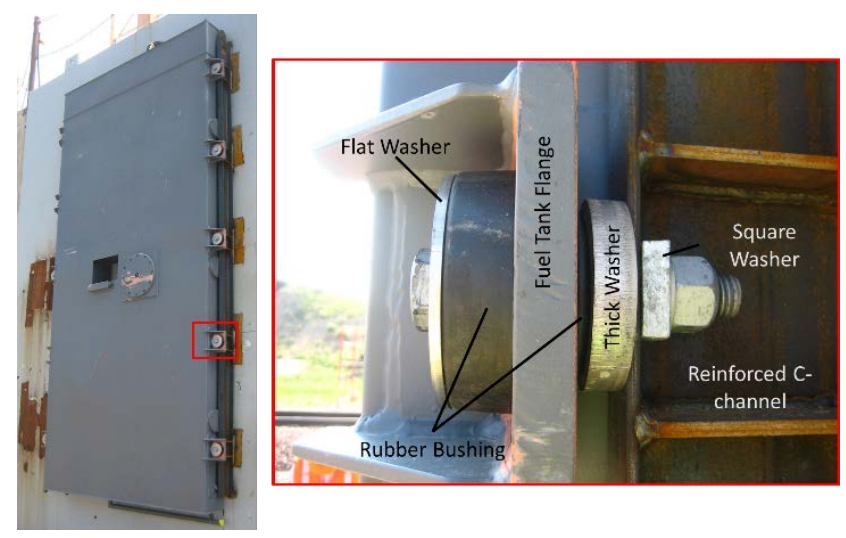

Figure 3. Typical Mounting Arrangement

\section{INSTRUMENTATION}

The objectives of the test were to characterize the fuel tank behavior and assess the details of the test setup in creating a controllable dynamic impact condition. The primary measurement made during this test was the force-versusdisplacement behavior of the impact cart, which equates to measuring force-deflection of the fuel tank over the time the impact cart stays in contact with the tank. Table 1 lists instrumentation used in the impact test of DMU fuel tank No. 1. Four sets of tri-axial accelerometers were installed on the cart.

Table 1. Instrumentation for Impact Test of DMU Tank No.

\begin{tabular}{|c|c|}
\hline \multicolumn{2}{|c|}{$\mathbf{1}$} \\
\hline \hline Instrumentation & Channel Count \\
\hline Accelerometers & 12 \\
\hline Speed Sensors & 2 \\
\hline Total Data Channels & $\mathbf{1 4}$ \\
\hline Digital Video & $\mathbf{6 ~ C a m e r a s ~}$ \\
\hline
\end{tabular}

Accelerometers, speed transducers and a camera were mounted on the cart as indicated in Figure 4. The yellow rectangle represents the outer structure of the rail cart. The right side of this figure is the impact end (impactor not shown).

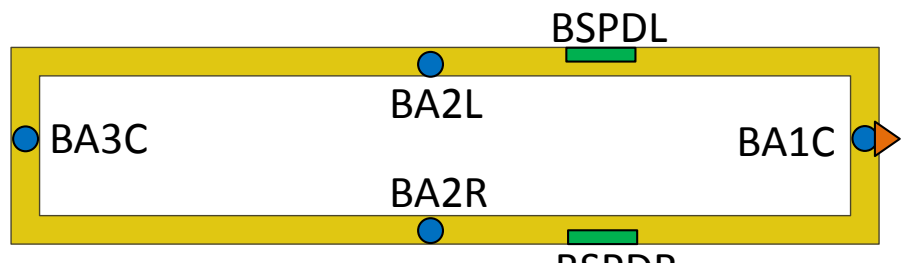

\section{BSPDR}

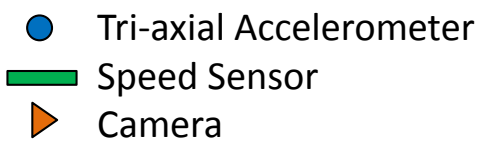

Figure 4. Schematic Showing Plan View of Impact Vehicle Carbody with Instrumentation Indicated

A total of six cameras were used to record the test, including one camera mounted to the impact cart itself. Two high-speed cameras were used to capture a view from above the tank, and to capture an isometric view of the impact. Additional cameras

This material is declared a work of the U.S. Government and is not subject to copyright protection in the United States. Approved for public release; distribution is unlimited. 
captured the impact from the left-side, right-side, isometrically, and from below the tank.

\section{TEST SPECIMENS}

Three conventional passenger locomotive fuel tanks, taken from locomotives retired from operation, have previously been used for testing in this program. These tanks are from F-40 type locomotives, and are referred to as Tanks 202, 232 and 234. The three tanks are of two different designs of underslung passenger locomotive tanks. While similar in size and capacity, the tanks each have minor design differences such as, shape, internal baffle layout, and material properties. While tanks 232 and 234 had the same exterior shape and dimensions, each of these tanks featured a unique baffle arrangement.

The test articles were used, in part, due to their availability. The fuel tanks showed wear and tear typical in service but were of sound structural integrity for testing. It should be noted that, while representative of a conventional style tank size and shape, they are not modern in design detail or method of construction. The fuel tanks were deemed suitable for preliminary tests of a dynamic impact scenario, in order to evaluate the test setup and its ability to provide the desired data.

The DMU tanks used in Phase 2 of this testing program were purchased new from a manufacturer. The fuel tanks are of a design that is currently in operation in the U.S. The DMU tanks do not meet FRA's existing requirements for locomotive fuel tanks (49 CFR 238, Appendix D) and are subject to operation under a waiver granted by FRA's Office of Safety.

The four tested tanks are shown, to scale, in Figure 5. The top row of images shows a bottom view of each tank, and the bottom row of images show an end-on view of each tank. From this figure, it is apparent that while the conventional tanks feature similar geometries, capacities, and mounting arrangements, the DMU tank is dissimilar in each of these categories. In addition to the obvious differences in external geometry between the DMU fuel tank and the conventional fuel tanks, each fuel tank features a unique baffle arrangement. This image illustrates one underlying reason for performing this research, the need to better understand how such a different design of fuel tank responds to an impact for which results for conventional locomotive fuel tanks are already established.

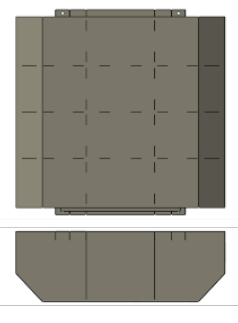

Tank 202

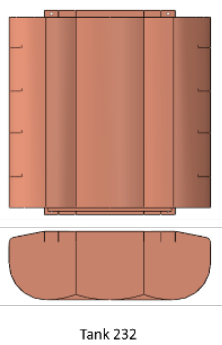

Tank 232

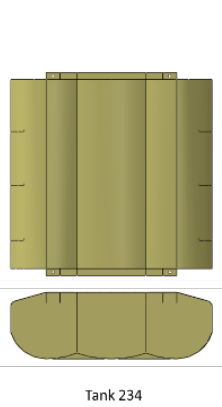

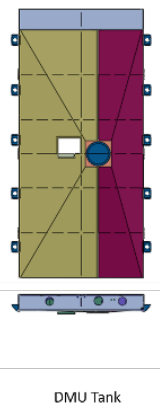

DMU Tank
Figure 5. Shown to Scale: Bottom (top row) and End (bottom row) Views of Tested Fuel Tanks

\section{TEST RESULTS}

The target speed for the blunt impact of DMU tank No. 1 was $11.5 \mathrm{mph}$ - the same target speed as for the test of Tank 234. The DMU tank was impacted by a 12 " by 12 ” indenter at $11.1 \mathrm{mph}$ on the bottom tank surface in a location centered between on a longitudinal and a lateral baffles. The combination of impact cart mass and impact speed resulted in an impact energy of approximately 57,620 foot-pounds. The tank deformed significantly across a large portion of its bottom sheet. Below the impact point, the tank attempted to pull away from the wall. The two sidewalls of the tank experienced buckling, as did the internal baffles. No material failure or fracture was found on the exterior of the tank after the test. Figure 6 shows a post-test photographs of the lower half of the DMU fuel tank.

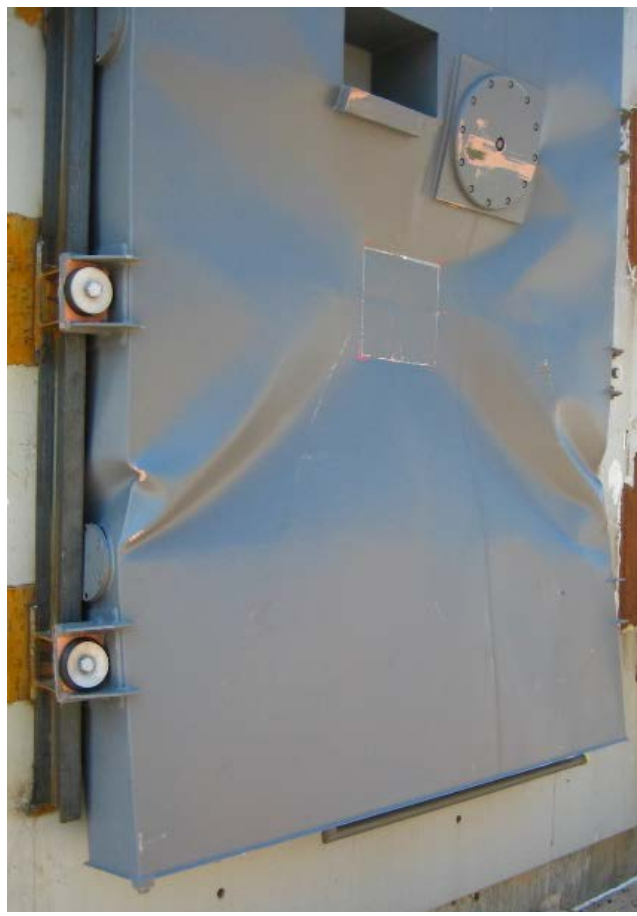

Figure 6. Post-test Photograph of DMU Fuel Tank No. 1; Bottom Half of Tank

The bottom sheet of the tank experienced a large " $X$ " shaped deformation pattern, radiating outward from each of the four corners of the area of contact under the impactor. As the zone of permanent deformation to the bottom sheet of the tank reached the edges of the bottom sheet, the sidewalls of the tank experienced buckling damage. This buckling damage is shown in greater detail in Figure 7.

This material is declared a work of the U.S. Government and is not subject to copyright protection in the United States. Approved for public release; distribution is unlimited. 


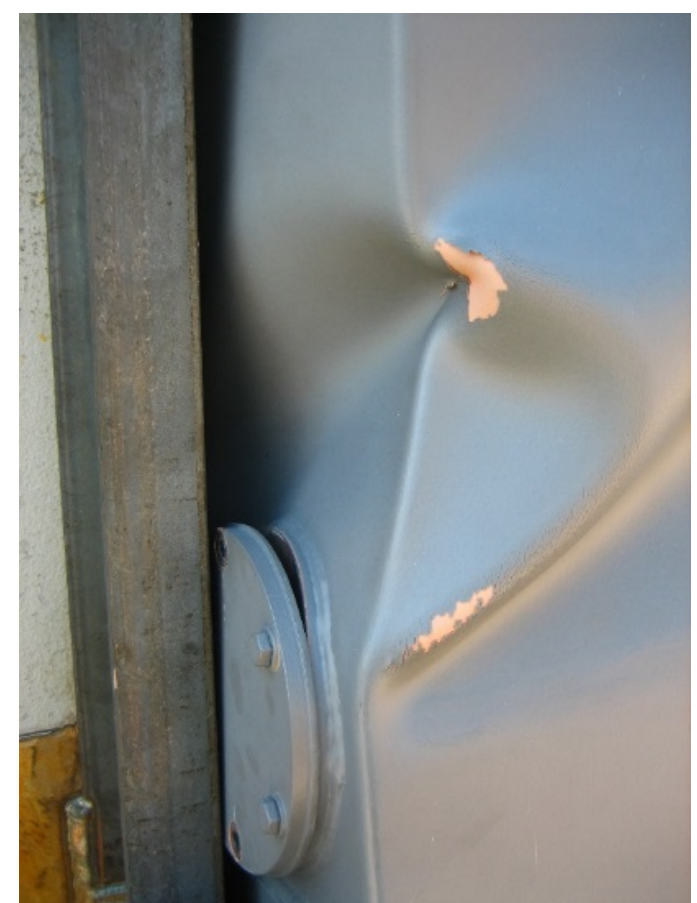

Figure 7. Post-test Photographs of DMU Fuel Tank No. 1 Showing Buckled Sidewall

Because the tank was mounted to the C-channels through rubber bushings, the lower portion of the tank was able to pull away from the wall in response to the impact. This behavior is shown in Figure 8.

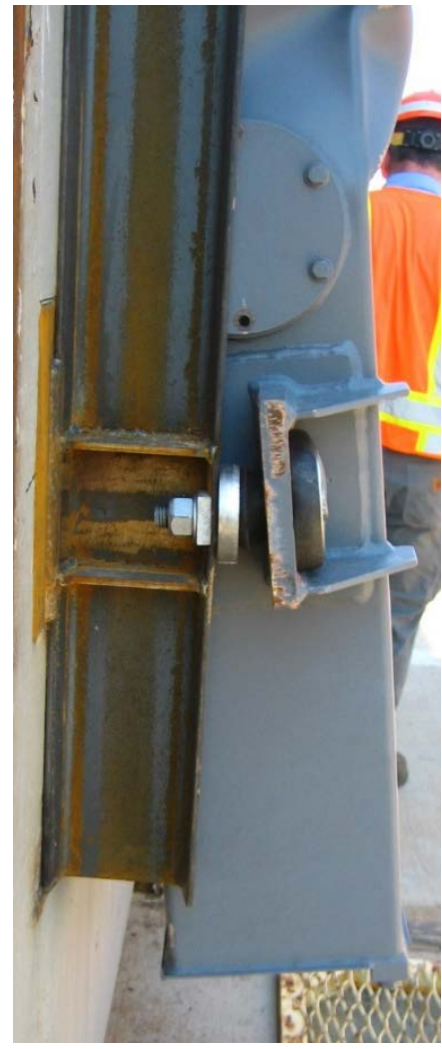

Figure 8. Post-test Photograph Showing Tank Pulling Away from Wall

\section{ACCELEROMETER DATA}

The longitudinal accelerometer at cross-section 1, on the lateral cross member at the impacting end of the cart, experienced ringing that persisted after application of a CFC60 filter; those results are excluded from any average results presented in this paper. The remaining three longitudinal accelerometers were filtered using a channel frequency class (CFC) 60 filter, consistent with the methods of Reference [10]. Forces were obtained from the accelerometers at cross sections 2 (left and right sides) and 3 (center line) by multiplying the full mass of the cart by the acceleration measured at each location. The forcetime histories from these three locations are shown in Figure 9. In spite of some residual oscillations in the measured data, there is relatively good agreement between all three accelerometers.

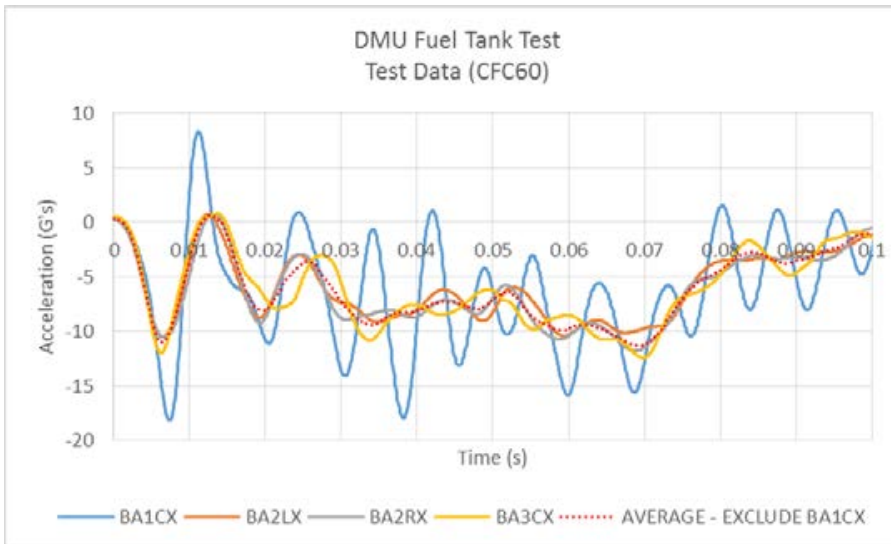

Figure 9. Acceleration-time Histories from Test

The velocity-time history of the impact cart was obtained by integrating the acceleration-time data. Similarly, the displacement-time history was obtained by integrating the velocity-time history. The impact cart had a maximum displacement of approximately 8.2 inches before being stopped and rebounding from the impacted tank. The displacement-time histories from the test are shown in Figure 10.

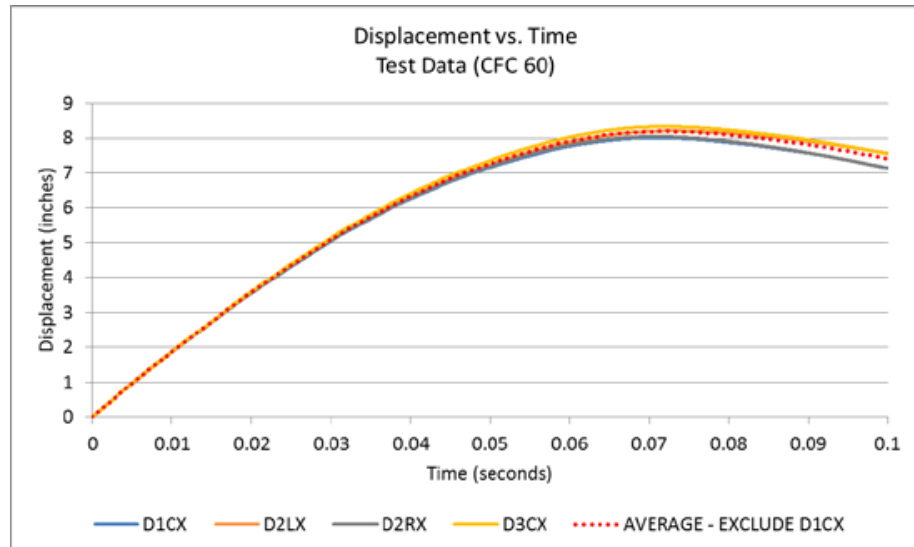

Figure 10. Displacement-time Histories from Test

\section{ANALYTICAL COMPARISONS}

Pre-test finite element analysis (FEA) was performed to help establish the desired impact speed. The pre-test model was

This material is declared a work of the U.S. Government and is not subject to copyright protection in the United States. Approved for public release; distribution is unlimited. 
assembled and meshed using the Abaqus/CAE software, and the simulation was executed in Abaqus/Explicit software [7]. The pre-test modeling was performed in two stages. The first stage used a rigid impactor and an estimated test speed, and the second phase used a deformable impactor attached to a deformable impact cart and the actual test speed. While the second phase model was run immediately following the test (owing to the need to know the actual impact speed), the only further change to the model was the replacement of the rigid impactor with a deformable one. Therefore, both models are referred to throughout this paper as "pre-test" models, as neither model was tuned or adjusted to better match the test results.

Detailed information on the geometry of the DMU fuel tank was provided by the manufacturer of the tank as part of the purchase of the tank. The information included manufacturing drawings as well as digital geometry that was used as a starting point for the tank geometry in the FE model. The tank model includes detailed geometry of the outer surfaces of the tank, internal baffles, and external mounting brackets and pads. The tank was modeled as a series of discrete parts that are attached to one another via tied constraints at the locations where actual parts would be attached via welding in the tank assembly. The tied constraints between parts constrain all six degrees-of-freedom (three translational and three rotational) and cannot fail. In this way, the constraints represent a perfectly-welded connection between parts.

In addition to modeling the tank, the pre-test FE model included a deformable impact cart, a deformable 12-inch by 12-inch impactor attached to the cart, and a representation of a rigid impact wall and C-channels. The deformable cart was adapted from a model originally assembled for a previous impact testing program [6]. The pre-test FE model also featured deformable rubber bushings and bolts to represent the mounting of the tank to the C-channels. An annotated illustration of the pre-test FE model is shown in Figure 11.

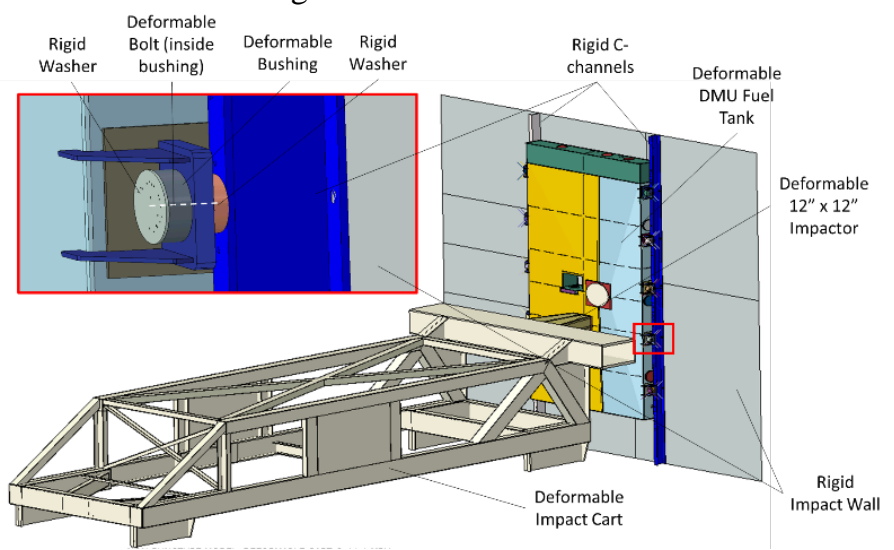

Figure 11. Pre-test FE Model with Annotations

While the tank drawings included information on the material specifications of the different parts used to make the tank, no test data from the actual materials of construction were available. Because elastic-plastic material behaviors needed to be defined in the pre-test FE model, this behavior had to be approximated based on available information, and would be updated with actual test data after the impact test. The tank featured two different steel alloys, S235 and S355. For each material, a value of $200 \mathrm{GPa}$ was used for Young's modulus. Because excising coupons from the tank prior to the test for tensile testing could potentially compromise the integrity of the tank as a test article, other sources of plastic stress-strain data were sought for use in the pre-test FE model. The input data for the S235 and S335 materials were adapted from stress-strain data published by a steel manufacturer [11]. A piecewise material model was defined for both materials as a function of true stress and true plastic strain. These material responses are shown in Figure 12.

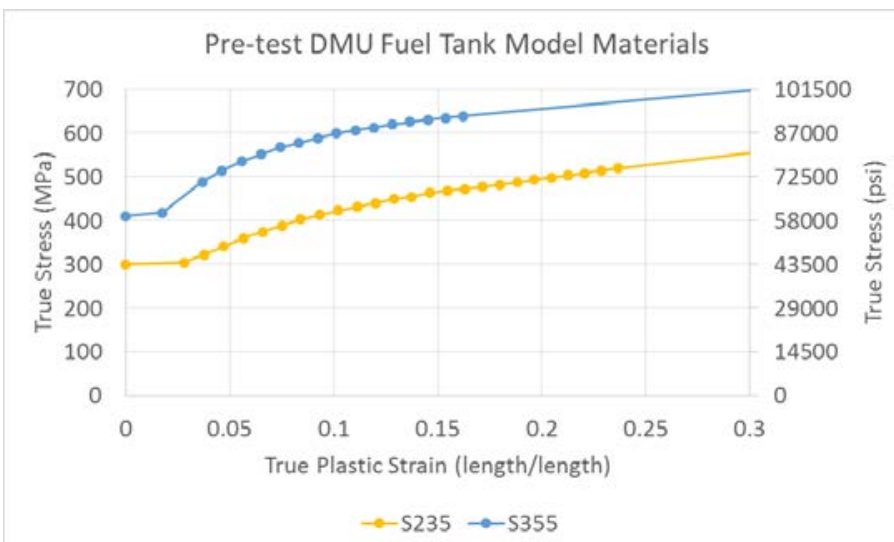

Figure 12. Plastic Stress-strain Behaviors used in Pre-test FE Models

In the pre-test model, material failure and fracture were approximated using a simplified constant strain-to-failure. When the plastic equivalent strain (PEEQ) in an element reached 0.4 , the element was assumed to have failed and its stiffness began to degrade. An energy-based damage evolution model was used to implement this reduction in stiffness until the element was removed from the analysis. Because actual test results did not exist for the pre-test material characterization, a conservative value was chosen for the fracture energy criterion. The Abaqus software documentation recommends against using a value of 0 for damage evolution, as that can lead to model instabilities. Thus, a small value of $1.0 \mathrm{~N}-\mathrm{mm} / \mathrm{mm}^{2}$ (fracture energy per unit area) was chosen for the pre-test material failure models.

The pre-test FE model included the rubber bushings used in mounting the tank. As an approximation of the rubber material, the pre-test FE model used material properties for a hyperelastic rubber air spring provided as an example problem in the Abaqus software documentation [12]. The deformable bolts that ran through the air springs were modeled as elastic beam elements having a cylindrical cross-section and using an elastic steel material as a simplified representation of the actual bolts.

The model was predominantly composed of shell elements and rigid elements, with a small number of continuum and beam elements used to model the bushings and bolts used to mount the tank. A summary of the deformable elements used in the model is given in Table 2. Additional rigid elements were used to define

This material is declared a work of the U.S. Government and is not subject to copyright protection in the United States. Approved for public release; distribution is unlimited. 
the impact wall, C-channels between the tank and the wall, and flat washers on top of the bushings.

Table 2. Summary of Deformable Elements in Pre-test Model

\begin{tabular}{|c|c|c|}
\hline Part Name & $\begin{array}{c}\text { Element } \\
\text { Type } \\
\end{array}$ & $\begin{array}{c}\text { Number of } \\
\text { Elements } \\
\end{array}$ \\
\hline \multirow{2}{*}{ Deformable Cart } & $\begin{array}{c}\text { Reduced } \\
\text { Integration } \\
\text { Quadrilateral } \\
\text { Shell (S4R) } \\
\end{array}$ & 66,141 \\
\hline & $\begin{array}{c}\text { Reduced } \\
\text { Integration } \\
\text { Triangular } \\
\text { Shell (S3R) }\end{array}$ & 126 \\
\hline $\begin{array}{c}\text { Deformable } \\
12 \text { x } 12 \text { Impactor }\end{array}$ & $\begin{array}{c}\text { Reduced } \\
\text { Integration } \\
\text { Quadrilateral } \\
\text { Shell (S4R) } \\
\end{array}$ & 23,718 \\
\hline \multirow{3}{*}{ Deformable Tank } & $\begin{array}{c}\text { Fully- } \\
\text { integrated } \\
\text { Quadrilateral } \\
\text { Shell (S4) }\end{array}$ & 7,087 \\
\hline & $\begin{array}{c}\text { Reduced } \\
\text { Integration } \\
\text { Quadrilateral } \\
\text { Shell (S4R) }\end{array}$ & 171,935 \\
\hline & $\begin{array}{c}\text { Reduced } \\
\text { Integration } \\
\text { Triangular } \\
\text { Shell (S3R) } \\
\end{array}$ & 2,987 \\
\hline $\begin{array}{c}\text { Deformable } \\
\text { Rubber Bushing }\end{array}$ & $\begin{array}{l}\text { Reduced } \\
\text { Integration } \\
\text { Hexahedral } \\
\text { Continuum } \\
\text { (C3D8R) }\end{array}$ & 8,400 \\
\hline Deformable Bolt & $\begin{array}{l}\text { Quadratic } \\
\text { Beam } \\
\text { (B32) }\end{array}$ & 10 \\
\hline
\end{tabular}

\section{Comparison of Pre-test FE Results and Test Results}

The first pre-test FE model was run at the target test speed of $11.5 \mathrm{mph}$, using a rigid impactor. Following the test, the pre-test model was re-run at the actual test speed of $11.1 \mathrm{mph}$, and using a deformable impact cart. No further modifications were made to the pre-test model. The maximum indentation and peak force from each model and from the test are compared in Table 3. Note that for the deformable cart FE model the reported value corresponds to an average of three longitudinal accelerometer values; the FE model using the rigid impactor has only a single result for either quantity and thus no averaging is necessary. Additionally, the deformable impactor FE results and the test data have each been filtered using a CFC60 filter in accordance with [10].
Table 3. Comparison of Maximum Indentation and Peak Force for Pre-test FE Models and Test Measurements

\begin{tabular}{|c|c|c|c|c|}
\hline & \multirow{2}{*}{ Impactor } & $\begin{array}{c}\text { Impact } \\
\text { speed }\end{array}$ & $\begin{array}{c}\text { Maximum } \\
\text { Indentation }\end{array}$ & $\begin{array}{c}\text { Peak } \\
\text { Force }\end{array}$ \\
\cline { 3 - 5 } & $\mathrm{mph}$ & inches & kips \\
\hline $\begin{array}{c}\text { Pre-test } \\
\text { Model 1 }\end{array}$ & Rigid & 11.5 & 8.2 & 156 \\
\hline $\begin{array}{c}\text { Pre-test } \\
\text { Model 2 }\end{array}$ & Deformable & 11.1 & 8.3 (avg) & $\begin{array}{c}157 \\
\text { (avg) }\end{array}$ \\
\hline Test & Deformable & 11.1 & 8.2 (avg) & $\begin{array}{c}141 \\
\text { (avg) }\end{array}$ \\
\hline
\end{tabular}

The force-displacement results from the test and the pre-test models are shown in Figure 13. As can be seen in this figure, both pre-test models capture the general behavior of the test measurements. It is apparent from this figure that the pre-test model using the deformable impactor captures the oscillations associated with the impact cart that are not present in the model using the rigid impactor.

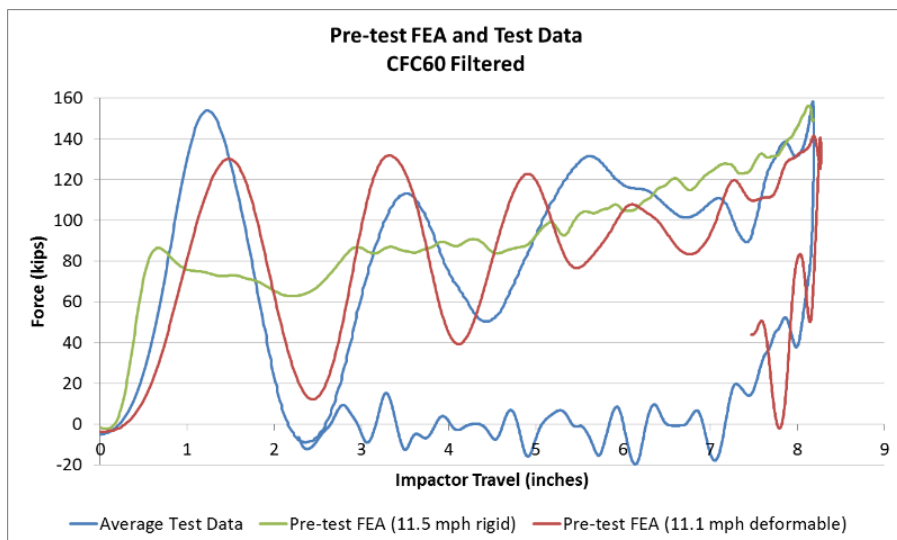

Figure 13. Average Force-displacement Results from Test and Pre-test FEA

The speed-time histories from the two pre-test FEA predictions and the test measurements are plotted in Figure 10. There is excellent agreement between the deformable cart FE results and the test measurements over the entire range of the impact event. The pre-test FE model using the rigid impactor was terminated shortly after the impactor rebounded from the tank; thus, the results are limited to approximately 0.07 seconds of impact time.

This material is declared a work of the U.S. Government and is not subject to copyright protection in the United States. Approved for public release; distribution is unlimited. 


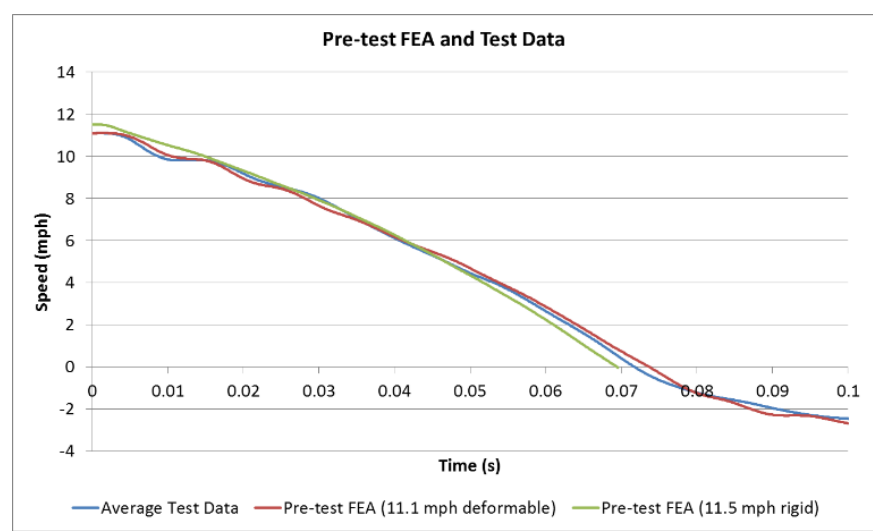

Figure 14. Impactor Cart Speed-time History from Test and Pre-test FEA

Both pre-test FE models also did an excellent job of capturing the deformation modes experienced by the fuel tank during the test. Figure 15 shows a side-by-side comparison of the deformed shapes of the bottom sheets of both FE models and the tested tank. All three results exhibit the same X-shaped deformation pattern, as well as buckling of the sidewalls in the same locations.

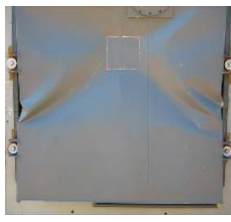

Post-test Photo

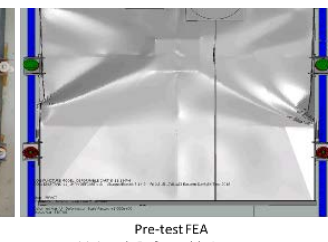

Pre-test FEA

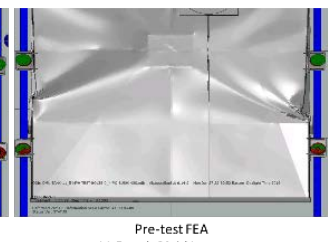

Pre-test FEA
Figure 15. Deformed Bottom Sheet from Post-test Photo (left), Pre-test Model with Deformable Impactor (center) and Pre-test Model with Rigid Impactor (right)

Following the test, a LiDAR-based scanning system was used to generate a 3D geometry file of the deformed tank. This geometry was used to generate a contour plot of indentation depth, using the surface away from the impact site as a zero-deformation datum. Similar contour plots were created for the two pre-test models. The three contours plots are compared to one another in Figure 16. It should be noted that while there is good agreement between the test and the models, the models were run for 0.1 seconds of simulated impact time. While that is enough time for the impactor to begin to rebound from the tank, the FE model may not have recovered all of its elastic deformation. Because the post-test scan was made after the impactor had completely rebounded, the post-test tank scan corresponds to geometry where all of the elastic deformation has recovered.

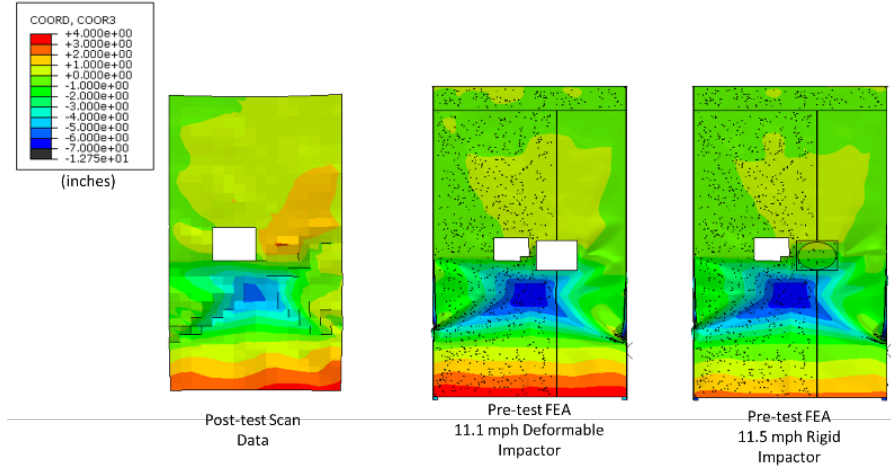

Figure 16. Contour Plots (inches) of Longitudinal Deformation from Post-test Scan (left), Pre-test Model with Deformable Impactor (center) and Pre-test Model with Rigid Impactor (right)

After the tank was removed from the impact wall, a portion of the top panel of the tank, which had been against the impact wall, was cut away. This permitted an inspection of the interior of the tank. The baffles adjacent to the impact site had buckled, as observed by a small material tear on the lateral baffle that was impacted. Both FE models captured the buckling reasonably well, but neither FE model included any material fracture. Interior views of the post-test tank and the deformed FE models are shown in Figure 17.

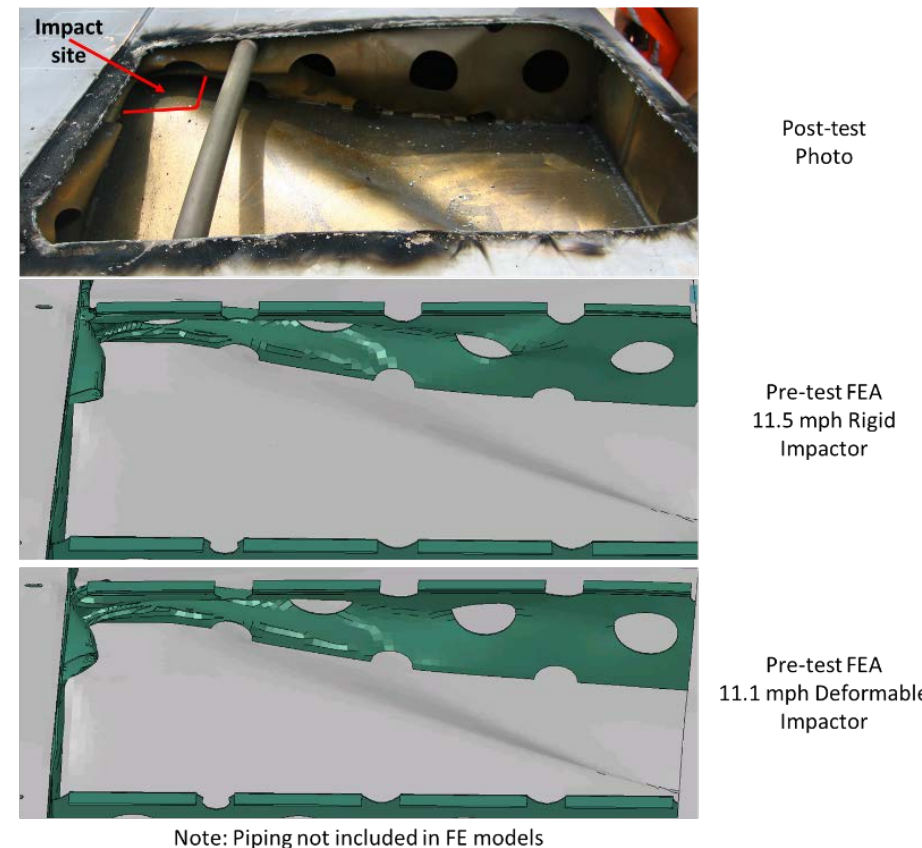

Figure 17. Damage to Baffles after Test (top),

Pre-test FEA with Rigid Impactor (center) and Pre-test FEA with Deformable Impactor (bottom)

\section{Comparisons of Tank Designs}

An impact test of conventional fuel tank 234 was conducted on August 20, 2014. Tank 234 was struck by the same impact cart as used in the DMU fuel tank test at a speed of $11.2 \mathrm{mph}$, which compares very closely with the DMU test's $11.1 \mathrm{mph}$. Neither fuel tank punctured under these similar impact conditions. The

This material is declared a work of the U.S. Government and is not subject to copyright protection in the United States. Approved for public release; distribution is unlimited. 
force-versus-impactor travel response of each fuel tank is shown in Figure 18.

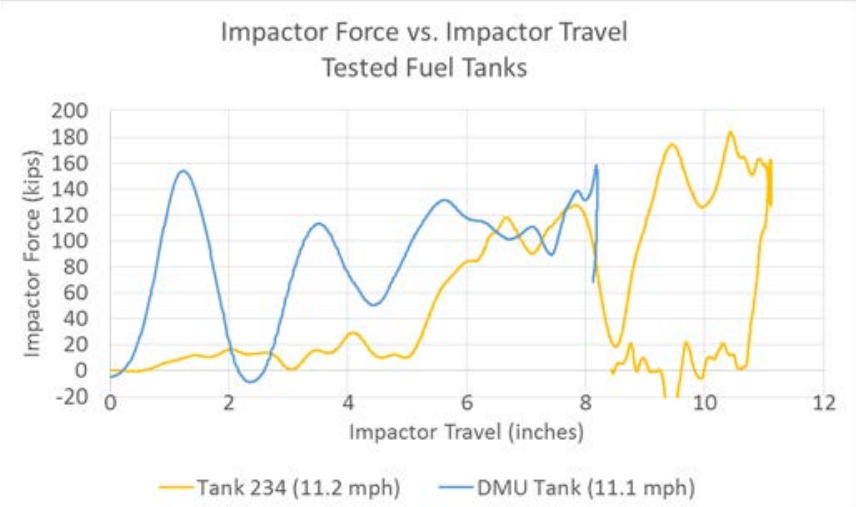

Figure 18. Impact Force versus Impactor Travel for Tank 234 and DMU Tank

While the impact conditions were nearly identical, the impact responses were very different. Tank 234 featured a very low initial force, as this tank features a gap between the interior of the bottom of the tank and the lateral baffles. The DMU fuel tank features baffles that are fixed to the bottom sheet. The DMU fuel tank experiences a high initial force, while the conventional tank does not experience a significant increase in stiffness until the bottom sheet closes the gap to the baffles. Both tanks experienced buckling of their respective baffles, which resulted in a temporary decrease in force. The deformed shapes of tank 234 and the DMU fuel tank are shown in Figure 19.
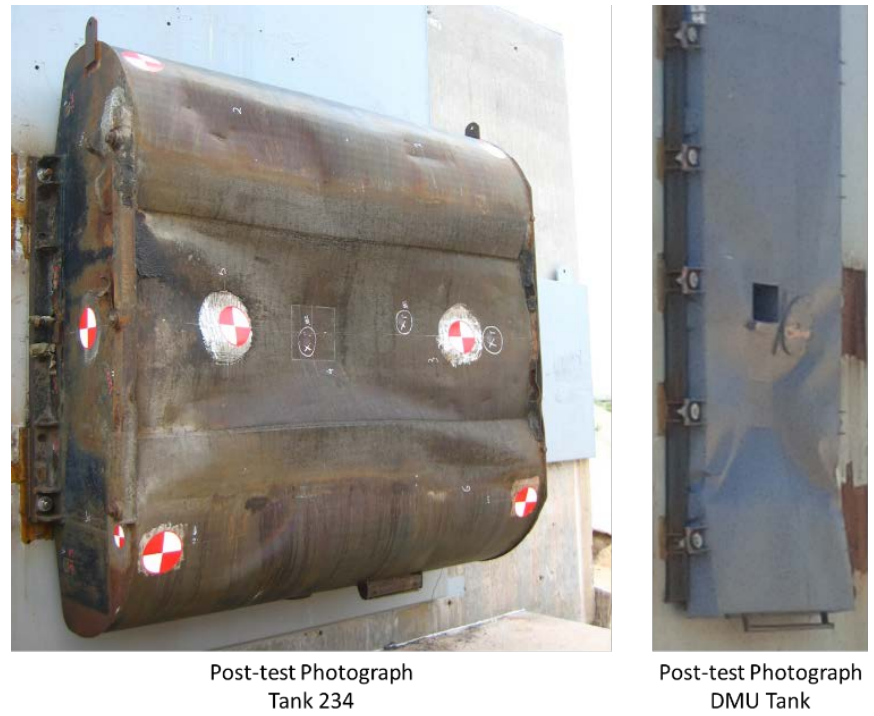

Figure 19. Deformed Shapes of Tank 234 (left) and DMU Fuel Tank (right)

Because it was so much stiffer, the DMU fuel tank experienced much less deformation compared to the conventional fuel tank. However, because the DMU had a smaller overall height than the conventional fuel tank, the maximum indentation experienced by the DMU tank represented a much larger reduction in height as a percentage of the initial height of the tank. Figure 20 and
Figure 21 show section views (tanks oriented as if mounted to bottom of a locomotive or DMU, respectively) taken from the FE model of tank 234 (which was described in [5]) and from the DMU fuel tank model with the deformable impactor. For each tank, the top image shows the initial configuration of the FE model, and the bottom image shows the deformed shape at approximately the time of maximum indentation. From these images, it is apparent that the DMU fuel tank has very little additional ability to crush before the impactor would encounter the rigid impact wall, while tank 234 can undergo a significant amount of additional deformation before crushing solidly. This difference in crush distance may play a role in puncture resistance of the two tanks, as it is expected that tank 234's bottom sheet would puncture before the 12" x 12" impactor would cause a sufficiently large deformation to encounter the impact wall. Further analyses of the response of the DMU tank under additional impact conditions, including different speeds, are planned for post-test modeling activities.

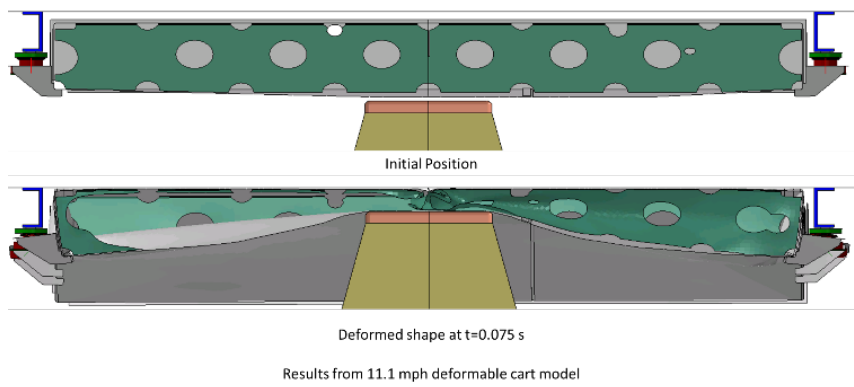

Figure 20. Initial and Deformed ( $t=0.075$ s) FE Models for DMU Fuel Tank

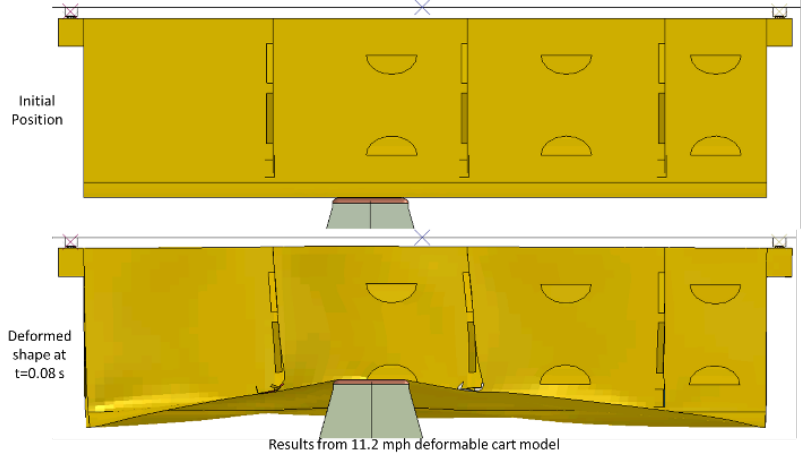

Figure 21. Initial and Deformed ( $t=0.08 \mathrm{~s})$ FE Models for Tank 234

\section{NEXT STEPS}

Research efforts are underway to draw comparisons between the requirements of the CFR [8] and the testing efforts through FE modeling. The outcomes of this effort will help further the understanding of how fuel tanks of an alternative design respond to the loads required under the CFR. Additionally, because the three conventional fuel tank test specimens were from retired locomotives that pre-date the existing regulations, the models developed in testing will be used to assess whether the tanks meet the existing requirements.

Post-test modeling of the DMU fuel tank will include re-running the model using the actual material properties measured in

This material is declared a work of the U.S. Government and is not subject to copyright protection in the United States. Approved for public release; distribution is unlimited. 
tensile tests after the test and the actual test speed. The model can then be used to examine other impact conditions, such as different impact locations on the tank, different impactor shapes and sizes, and different impact speeds to better understand how these parameters affect the overall tank response to impacts. Further, a more detailed fracture modeling technique can be implemented using the tensile coupon data to determine the required parameters described in Reference [9].

Plans are underway to scope a series of tests for evaluating an oblique impact to a fuel tank, similar to those that can occur in a raking impact to the side of the tank or an oblique impact to the bottom or end of the tank. The results of the tensile tests conducted on DMU tank No. 1 have been used to update the material behaviors in the FE model, so that future analyses will be more representative of the detailed DMU tank behavior. This will assist in planning tests of the remaining two DMU fuel tank specimens.

\section{ACKNOWLEDGEMENTS}

The fuel tank research is part of the Equipment Safety Research Program sponsored by the Office of Research and Development of the FRA. This work is monitored by Program Managers in the Office of Rolling Stock Research. FRA staff at TTC helps to coordinate efforts between FRA, Volpe and TTCI.

The authors would like to acknowledge Volpe Center colleague Dr. A. Benjamin Perlman for his ongoing technical advice and support in the research discussed in this paper. The authors would also like to acknowledge Volpe center colleagues, Shaun Eshraghi and Kane Vinson for their contributions to the development of the fuel tank models.

\section{REFERENCES}

[1]. Jacobsen, K., "Fuel Tank Crashworthiness: Loading Scenarios," American Society of Mechanical Engineers, Paper No. JRC2011-56077, March 2011. http://ntlsearch.bts.gov/tris/record/ntl/37914.html

[2]. Jacobsen, K., Carolan, M., Perlman, A.B., "Conventional Fuel Tank Blunt Impact Tests: Test and Analysis Results,” Proceedings of the 2014 Joint Rail Conference, JRC20143786, April 2014. http://ntlsearch.bts.gov/tris/record/ntl/51599.html

[3]. Jacobsen, K., Llana, P., Carolan, M., Sullivan, L., "Fuel Tank Integrity Research: Fuel Tank Analyses and Test Plans,” Proceedings of the 2013 ASME/IEEE/ASCE Joint Rail Conference, JRC2013-2425, April 2013. http://ntlsearch.bts.gov/tris/record/ntl/50984.html

[4]. Jacobsen, K., Llana, P., Carolan, M., Llana, P., "Test Requirements of Locomotive Fuel Tank Blunt Impact Tests,” Proceedings of the 2013 ASME Rail Transportation Division Fall Technical Conference, RTDF2013-4701, October 2013. http://ntlsearch.bts.gov/tris/record/ntl/48594.html

[5]. Jacobsen, K., Carolan, M., "Results of a Conventional Fuel Tank Blunt Impact Test," American Society of Mechanical Engineers, Paper No. JRC2015-5759, March 2015. http://ntlsearch.bts.gov/tris/record/ntl/54927.html
[6]. Muhlanger, M., Llana, P., Tyrell, D. "Dynamic and QuasiStatic Grade Crossing Collision Tests," American Society of Mechanical Engineers, Paper No. JRC2009-63035, March 2009.

http://ntlsearch.bts.gov/tris/record/ntl/43034.html

[7]. Abaqus version 6.14. Dassault Systems Simulia Corp, Providence, RI, 2014.

[8]. U.S. Department of Transportation, Federal Railroad Administration, Code of Federal Regulations, Title 49, Part 238, Appendix D— "Requirements for External Fuel Tanks on Tier I Locomotives".

[9]. Y.W. Lee and T. Wierzbicki, "Quick Fracture Calibration for Industrial Use," Impact \& Crashworthiness Laboratory Report No. 115, August 2004.

[10]. SAE International. Instrumentation for Impact Test, Part 1, Electronic Instrumentation. SAE J211-1 (1995).

[11]. Hechler, O., Axmann, G., and Donnay, B. The Right Choice of Steel - According to the Eurocode. ArcelorMittal. June 26, $2009 . \quad$ Luxembourg. http://sections.arcelormittal.com/uploads/tx_abdownloads/f iles/25_The_right_choice_of_steel_Ver2.pdf

[12]. Abaqus Example Problems Guide 6.14. "1.1.9 Hydrostatic Fluid Elements: Modeling an Airspring." Dassault Systems Simulia Corp, Providence, RI, 2014.

This material is declared a work of the U.S. Government and is not subject to copyright protection in the United States. Approved for public release; distribution is unlimited. 